This is an Accepted Manuscript of an article published by Taylor \& Francis in Advances in Applied Ceramics on 05/04/17, available online: http://www.tandfonline.com/doi/full/10.1080/17436753.2017.1309800 


\title{
Densification behaviour and physicomechanical properties of porcelains prepared using spark plasma sintering
}

\author{
Wirat Lerdprom a, ${ }^{*}$, Salvatore Grasso ${ }^{\mathrm{b}}$, Doni D. Jayaseelan ${ }^{\mathrm{c}}$, Michael J. \\ Reece ${ }^{b}$ and William E. Lee ${ }^{a}$ \\ ${ }^{a}$ Centre for Advanced Structural Ceramics, Department of Materials, Imperial College London, SW7 \\ 2AZ, UK \\ b School of Engineering and Materials Science, Queen Mary University of London, E1 4NS, UK \\ c School of Mechanical and Aerospace Engineering, Kingston University London, SW 15 3DW, UK \\ Corresponding Author: \\ E-mail: w.lerdprom14@imperial.ac.uk (W. Lerdprom)
}

\begin{abstract}
Porcelain powder was consolidated using spark plasma sintering (SPS) at a constant heating rate of $100^{\circ} \mathrm{C} / \mathrm{min}$ to peak temperatures ranging from $1000-1200^{\circ} \mathrm{C}$ and was observed to sinter at relatively low temperature $\sim 920^{\circ} \mathrm{C}$ under the SPS conditions while conventional sintering requires $\sim 1050^{\circ} \mathrm{C}$. SPS produced densification rates about 10 times greater than conventional sintering. The dwelling step at the optimal peak temperature was negligible due to rapid flow of the molten glass assisted by applied pressure. SPSed samples exhibited denser microstructures resulting in improved physicomechanical properties compared with conventionally sintered samples such as improved apparent bulk density from 2.38 to $2.48 \mathrm{~g} / \mathrm{cm}^{3}$, improved Vickers hardness from 2-4 to 6-7 GPa, and improved fracture toughness from 2-3 to 4-6 MPa $\mathrm{m}^{1 / 2}$.
\end{abstract}

\section{Keywords:}

Porcelains, Spark plasma sintering, Field assisted sintering, Densification, Viscous flow sintering 


\section{Introduction}

Porcelains are versatile materials used in many applications from household to engineering appliances [1-4]. They are produced from natural raw materials which are abundant in the earth' $s$ crust (clays, feldspars and quartz). To produce a porcelain

product, the three components are weighted proportionally depending on the technological needs, then the homogeneously mixed porcelain body (either wet or dry mixed) can be shaped by various techniques (i.e. slip casting for complex-shape products or dry pressing for simple geometries). A green-shaped porcelain is subjected to a sintering process which involves several chemical reactions resulting in a strong body. Sintered porcelains commonly contain mullite, residual feldspars and undissolved quartz all embedded in a glassy matrix.

The presence of liquid glassy phase (initially the molten feldspars, although later the products of their reaction with other phases present) in porcelains during sintering promotes viscous flow sintering or vitrification via capillary pressure [3, 5]. The factors controlling densification by vitrification are the fraction and viscosity of the liquid glassy phase formed as well as particle size distribution of the powder compact [5]. The amount of liquid glass formed is commonly $25-50$ vol\%, which enables dense porcelains to be produced in industrially acceptable time scales [6]. The viscosity of the liquid glassy phase is strongly controlled by its chemistry and sintering temperature. A small particle size of the starting powder produces high capillary pressure. However, a combination of large amount and low viscosity of liquid glass during the sintering process can result in significant undesired pyroplastic deformations [5].

The volume fraction of liquid glass for vitrification is a strong function of given by the amount of fluxing agents available. Feldspars, a common fluxing agent, start to form eutectic melts (for potash feldspar the eutectic melt forms at $990^{\circ} \mathrm{C}$ while the eutectic melt of soda feldspar forms at $\sim 1050^{\circ} \mathrm{C}$ ) at relatively low temperatures compared to their melting points $\left(1110-1170^{\circ} \mathrm{C}\right)$ ) which is assisted by highly-reactive amorphous silica liberated from the decomposition of metakaolinite. The melting of feldspar is strongly controlled by dwell time and temperature while the effect of heating rate can be negligible [6]. 
During the sintering process, kaolinite undergoes several chemical and structural transformations. The release of its chemically bound water (dehydroxylation) at about $450-600^{\circ}$ leads to the formation of metakaolinite having a disordered crystal structure. Then metakaolinite is converted into a spinel phase $\left(\mathrm{Si}_{3} \mathrm{Al}_{4} \mathrm{O}_{12}\right)$ in the temperature range $950-1050^{\circ} \mathrm{C}$ with consequent formation of highly-reactive amorphous silica as a byproduct. However, some authors suggest that the metakaolinite transformation can form Al-Si spinel, $\mathrm{Y}$-alumina or primary mullite depending on the chemistry [2, 79]. Mullite in porcelains has been reported as primary, secondary and tertiary depending on its source and aspect ratio. Primary mullite is generally located in the clay relicts exhibiting a small aspect ratio. Secondary mullite is found embedded in the glassy matrix (feldspar relicts) with high aspect ratio, while tertiary mullite, which is rarely formed, is located at the interface between alumina particles and glassy matrix [10]. Quartz is another important component since it controls both the green and fired physicomechanical properties of porcelains; undissolved quartz can cause cracking during cooling because its transformation from the alpha to beta polymorphs. The dissolution of quartz starts above $1200^{\circ} \mathrm{C}$ and increases as a function of temperature, but it is heating rate independent [6].

Spark plasma sintering (SPS), thanks to its ability to provide much higher heating rates and shorter processing times compared to conventional sintering has driven in the past 30 years the development of novel materials/microstructures. The advantages of SPS over conventional sintering are: (i) rapid heating and cooling rates produced by volumetric heating (in the case of conductive materials); (ii) shorter times and lower temperatures for sintering resulting from applied pressure and electric current effects; and (iii) smaller grain size due to shorter consolidation times. For insulating ceramics, the current flowing across the sample is negligible, and most of the heating is produced by direct Joule heating of the graphite die. Conversely, electric current is beneficial for conductive powder which heat can be generated internally in the materials bulk [11].

Only a few researchers have attempted to consolidate porcelain using SPS [12]. In this work a commercial porcelain powder was used as a starting material to study the effect of temperature and dwell time at a constant heating rate during SPS processing. The results are compared with the well-established conventional sintering-vitrification mechanisms for on porcelains. 


\section{Experimental}

The material used in this study was provided by a porcelain factory in Thailand and was mainly composed of kaolinite, albite (soda feldspar) and quartz. The starting material was obtained in a spray dried powder form with average granule size between

$300-400 \mu \mathrm{m}(\sim 60 \%)$ and mean particle size $\left(D_{50}\right)$ of $10 \mu \mathrm{m}$. The powders were sintered

using an SPS furnace (FTC HP D25; FCT Systeme GmbH, Rauenstein, Germany). The powder was poured into a $20 \mathrm{~mm}$ diameter graphite die and was sandwiched between $0.3 \mathrm{~mm}$ thick graphite foils. The die was placed between the graphite punches which acted as electrodes, and graphite felts were placed around the die to reduce heat loss. A constant vacuum of $5 \mathrm{~Pa}$ was used during the sintering. Three different maximum SPS processing temperatures were used, 1000, 1100, and $1200^{\circ} \mathrm{C}$, with a constant heating rate of $100 . \mathrm{C} / \mathrm{min}$, constant dwell time of $5 \mathrm{~min}$, and constant pressure of $25 \mathrm{MPa}$ (the pressure was applied cold and left on until the end of the processing to study the effect of temperature). Four dwell times were also used, $0,5,10$ and $15 \mathrm{~min}$, at $1100^{\circ} \mathrm{C}$ to study the effect of time. The samples were then cooled to room temperature at $100{ }^{\circ} \mathrm{C} / \mathrm{min}$. Temperature was measured using a pyrometer focused inside a hole in the top punch at a distance of $4 \mathrm{~mm}$ from the sample.

For the purpose of comparison, the same porcelain powder was uniaxially coldpressed at $35 \mathrm{MPa}$ into $13 \mathrm{~mm}$ diameter and $7 \mathrm{~mm}$ thick pellets in a steel die. The pellets were dried overnight at $110^{\circ} \mathrm{C}$ then sintered at rates of $5^{\circ} \mathrm{C} / \mathrm{min}$ to the sintering temperatures of $1000,1100,1150,1175$, and $1200^{\circ} \mathrm{C}$ and held for 15 minutes at the respective sintering temperatures and cooled to $700^{\circ} \mathrm{C}$ at $30^{\circ} \mathrm{C} / \mathrm{min}$ followed by furnace cooling to room temperature.

After sintering, sample surfaces were ground and polished using silicon carbide abrasive sheets $(800,1200,2400$ and 4000 grits) prior to testing. Physical properties such as apparent bulk density and water absorption were determined using Archimedes' s method following the ASTM-C20-00 standard. Phase analyses of

sintered samples were carried out using X-ray diffraction (XRD, Bruker D2 Phaser, Madison, WI, USA). XRD data were collected from $15^{\circ}$ to $65^{\circ} 2 \theta$ with CuKa

software, Pan Analytical). 
$(\lambda=0.154 \mathrm{~nm})$ at $30 \mathrm{kV}$ and $10 \mathrm{~mA}$ with a step size of $0.03^{\circ}$ and a count time of $1 \mathrm{~s}$.

software, Pan Analytical). 
The microstructures of the samples were examined using a scanning electron microscope, SEM, (JEOL JSM-5610LV) with an accelerating voltage of $20 \mathrm{kV}$, under high vacuum using secondary electron imaging.

Microhardness testing (Vickers Hardness: HV) was carried out using a microhardness tester (Zwick, HV) at a constant indentation load of $9.807 \mathrm{~N}$ and indentation duration of 10 s. The HV was calculated from the equation: $\mathrm{HV}=1.8544 \mathrm{P} / \mathrm{d}^{2}$ (P: indentation load, $(\mathrm{N})$ and $\mathrm{d}$ : Vickers dimension $(\mu \mathrm{m})$ ). Fracture toughness $(\mathrm{KIC})$ was calculated using the equation: $\mathrm{KIC}=0.16(\mathrm{HV})\left(\mathrm{a}^{1 / 2}\right)(\mathrm{c} / \mathrm{a})^{-3 / 2}$ where $\mathrm{HV}=$ Vickers Hardness $(\mathrm{GPa})$, a is half of the indentation impression diagonal length and $\mathrm{c}$ is the crack length measured from the centre of the indentation to the crack tip [13]. The cracks were measured immediately after indentation using an optical microscope attached to the microhardness tester. Only well-defined cracks without chipping and termination at pores were considered and used in the calculation. 


\section{Results and discussion}

\subsection{Phase composition}

Fig.1a shows XRD patterns of the as-received porcelain powder and SPSed samples sintered at different temperatures of $1000-1200^{\circ} \mathrm{C}$. The as-received powder was composed mainly of albite $(A)$, kaolinite $(K)$ and quartz $(\mathrm{Q})$. Fig. 1a shows that after sintering at $1000^{\circ} \mathrm{C}$ under the SPS conditions the powder undergoes a slight phase change; the intensity of the kaolinite and albite peaks decreases compared to the asreceived powder. Mullite peaks become pronounced in the SPSed samples sintered at 1100 and $1200^{\circ} \mathrm{C}$ as well as a large hump observed at $20-30^{\circ}$, which indicates the formation of glassy phase from the melting of the albite. XRD also suggests that the fraction of glassy phase increases slightly at $1200^{\circ} \mathrm{C}$ due to quartz dissolution (confirmed by decreased of quartz peak intensity).
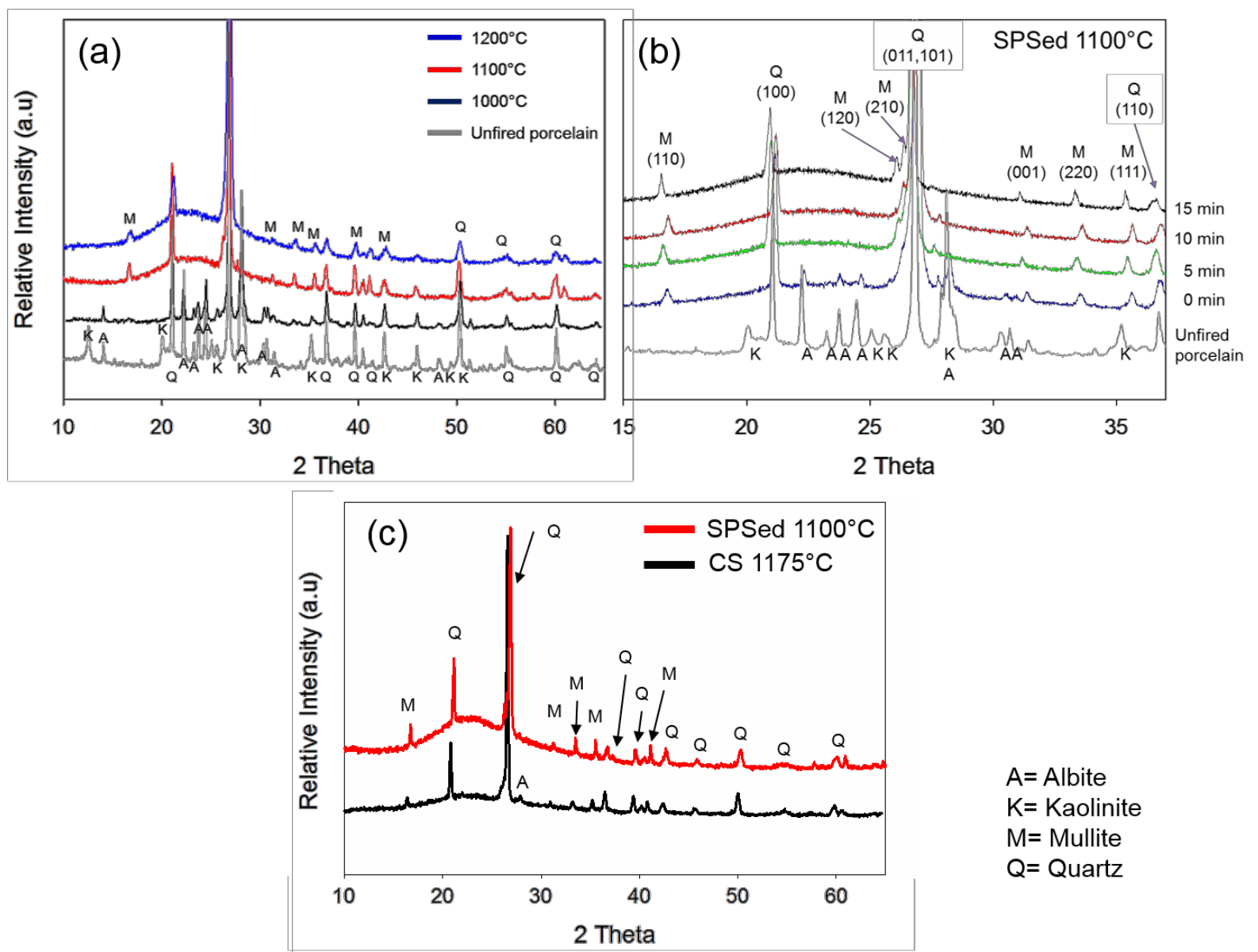

A $=$ Albite

$\mathrm{K}=$ Kaolinite

$M=$ Mullite

$Q=$ Quartz

Figure $1 \mathrm{XRD}$ of porcelain powder sintering using SPS with different (a) temperatures and (b) dwell times, and (c) comparison of SPSed and conventionally sintered samples. 
Fig. $1 \mathrm{~b}$ reveals the effect of dwell time on the SPSed samples sintered at $1100^{\circ} \mathrm{C}$. Mullite peaks are observed at 0 min and become more pronounced with increasing dwell time. At short dwell times of 0 and $5 \mathrm{~min}$, residual albite is still observed but vanishes after 15 min suggesting that it completely transforms to glass. The quartz peaks shift to lower angles, which may result from compressive stresses in the quartz lattice which are generated during the SPS processing. Fig.1c presents a comparison of fully dense samples sintered using conventional and the SPS. It can be seen that the SPSed $1100^{\circ} \mathrm{C}$ sample is composed of three major phases-mullite, glass and residual quartz while the conventionally sintered sample is composed of residual albite, mullite, glass and residual quartz. It is also clear that the SPSed sample contains more mullite, glass and less residual quartz.

\subsection{Densification}

Figure 2a shows the densification behaviour of the SPSed samples as a function of temperature in the range from $1000-1200^{\circ} \mathrm{C}$ with a constant heating rate of $100^{\circ} \mathrm{C} / \mathrm{min}$ and constant dwell time at $5 \mathrm{~min}$. The initial stage of sintering of the three samples starts with punch displacement between $25-400^{\circ} \mathrm{C}$, which is produced by a combination of cold compaction and particle rearrangement under applied pressure. The particle rearrangement is produced by the plate-like kaolinite particles which randomly arrange in the spray dried powder. Under the applied pressure the kaolinite particles tend to rearrange perpendicular to the compressive plane [14]. The punch displacement associated with the shrinkage of the samples at $400-500^{\circ} \mathrm{C}$ results from dehydroxylation of the clay species; the process involves losing the chemically bound water in their crystal structure, so the clay structure collapses under the applied pressure $[15,16]$. Between $600-900^{\circ} \mathrm{C}$, there is no further change in the punch displacement.

At $\sim 900^{\circ} \mathrm{C}$, a significant displacement is observed resulting from the melting of albite to form liquid glass. For the SPSed $1000^{\circ} \mathrm{C}$ sample, the punch displacement rate is small compared to the samples with higher firing temperatures, suggesting that the amount of liquid glassy phase produced is insufficient to promote significant densification. The punch continues to contract during the dwell step which is a consequence of further liquid glassy phase formation (albite continues to melt). However, the densification cannot be completed during the 5 min dwell time. The 
SPSed samples sintered at $1100^{\circ} \mathrm{C}$ shows large punch displacement as a consequence of the large amount of liquid glass produced with increasing temperature, and the glass formation is likely to be completed because there is no further densification during the dwell step. The same scenario was observed for the SPSed samples prepared at $1200^{\circ} \mathrm{C}$, which also showed no densification during the dwell step. However, the punch displacement shows expansion due to bloating.

Figure $2 \mathrm{~b}$ reveals the effect of dwell time on densification of the SPSed $1100^{\circ} \mathrm{C}$ samples. It can be reasoned from the high displacement rate that substantial volumes of liquid glass start to form at about $900^{\circ} \mathrm{C}$. Fig. $2 \mathrm{c}$-e shows the displacement rate of the SPSed sample as a function of temperature revealing that the punch starts to displace at $\sim 900^{\circ} \mathrm{C}$ and finishes at $\sim 1050^{\circ} \mathrm{C}$.
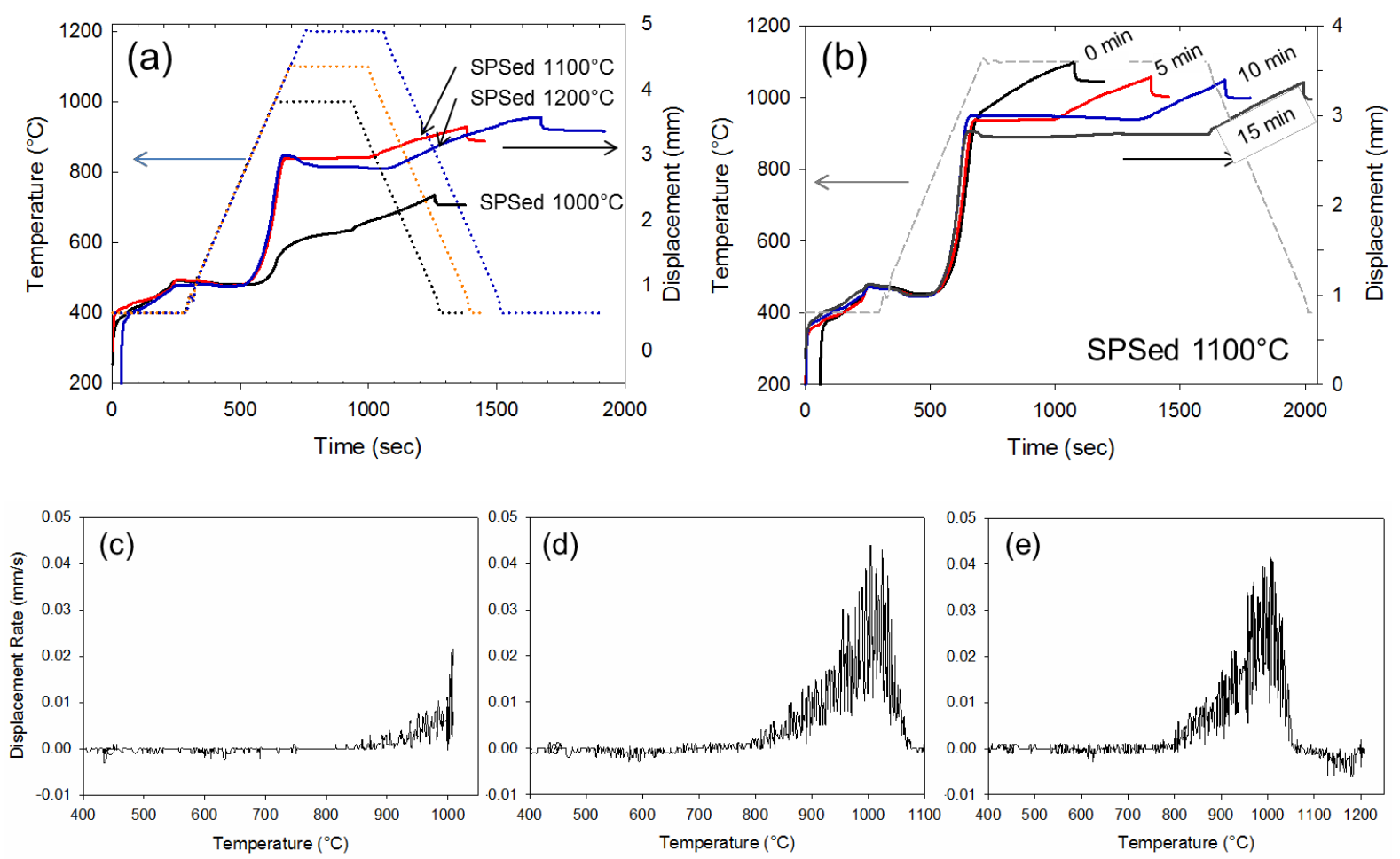

Figure 2 Densification behaviour of porcelain sintered using SPS as a function of (a) temperatures, and (b) dwell times, (c-e) are the displacement rate of the SPSed samples sintered at 1000,1100 and $1200^{\circ} \mathrm{C}$ respectively.

A comparison with conventional sintering (CS) suggests that SPS allows densification of this porcelain body to be achieved at a relatively low temperature $\left(1100^{\circ} \mathrm{C}, 25 \mathrm{MPa}\right)$ compared to a conventional sintering which is $1175^{\circ} \mathrm{C}$ in pressureless conditions (Fig.3a). These results suggest that applied pressure promotes a rapid densification 
rate via vitreous sintering. Because of its rapid heating in combination with applied pressure, the major benefit of SPS over conventional sintering is that the processing times for vitreous phase sintering can be significantly reduced.

The different densification of the samples sintered by different sintering processes can be highlighted by plotting the rate of change of the apparent bulk density as a function of the sintering temperature (Fig.3b). The densification rate of the SPSed samples is highest at $900-1000^{\circ} \mathrm{C}$ (time interval of 60 s) while the conventionally sintered sample has the highest rate at $1050-1100^{\circ} \mathrm{C}(600 \mathrm{~s})$. It should be noted that the densification rate of the conventional firing process is higher than the SPS because the rate is accelerated over the SPS cycle with an initial densification below $600^{\circ} \mathrm{C}$.
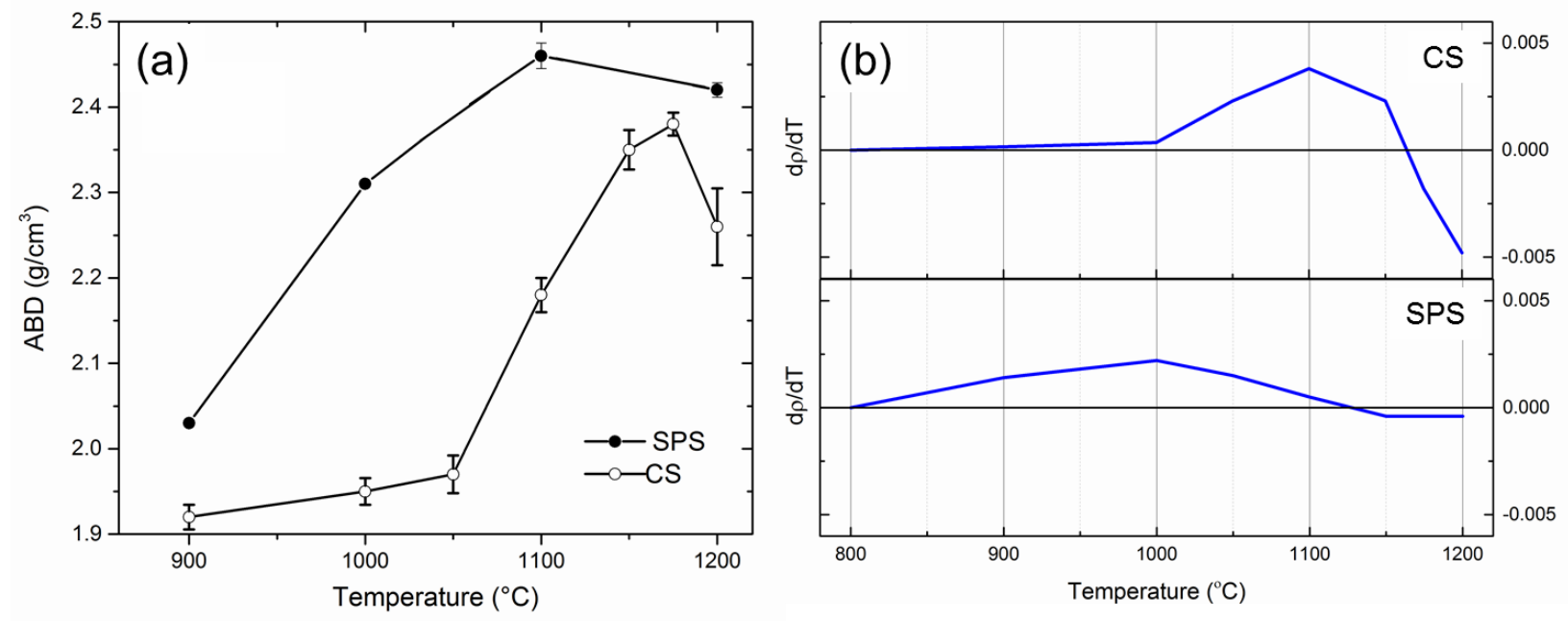

Figure 3. (a) Apparent bulk density (ABD) of the samples sintered using the SPS and the conventional sintering process (b) Rate of change of apparent bulk density, $\mathrm{d} \rho$ /dT sintering temperature.

\subsection{Physical Property}

Figure 4 shows the apparent bulk density (ABD) and water absorption (WA) of the SPSed samples as a function of temperature (Fig.4a) and dwell time (Fig.4b). The $A B D$ increases from $1000^{\circ} \mathrm{C}$ to $1100^{\circ} \mathrm{C}$ but decreases for $1200^{\circ} \mathrm{C}$. It is clear that increased $A B D$ is due to viscous flow sintering under applied pressure while decreased ABD likely arises from bloating. However, the WA of the samples at 1100 and $1200^{\circ} \mathrm{C}$ is similar at $\sim 0.01 \%$. The ABD result shows that SPS produces porcelains with higher density of $2.48( \pm 0.01) \mathrm{g} / \mathrm{cm} 3$ while the conventionally sintered sample (CS) is $2.38( \pm 0.02) \mathrm{g} / \mathrm{cm} 3$. Figure $4 \mathrm{~b}$ illustrates $A B D$ also decreases as a function of dwell 
time arising from the different mineralogical compositions (albite, mullite, quartz, and glass) also seen in Fig.1b. As previously mentioned, the SPSed samples at $1100^{\circ} \mathrm{C}$ with 0 and $5 \mathrm{~min}$ of dwell time have higher densities due to residual albite while the SPSed with 10 and $15 \mathrm{~min}$ of dwell time contain no albite (density of albite $=2.65 \mathrm{~g} / \mathrm{cm}^{3}$, mullite $=3.12 \mathrm{~g} / \mathrm{cm}^{3}$, quartz $=2.65 \mathrm{~g} / \mathrm{cm}^{3}$, and glass $=2.36( \pm 0.02) \mathrm{g} / \mathrm{cm}^{3}$, (the density of glass phase in porcelain with chemistry of $1\left(\mathrm{RO}+\mathrm{R}_{2} \mathrm{O}\right): 1.19( \pm 0.1) \mathrm{Al}_{2} \mathrm{O}_{3}: 11-18 \mathrm{SiO}_{2}$ in the unity molecular formula basis (UMF) [6, 17-19].
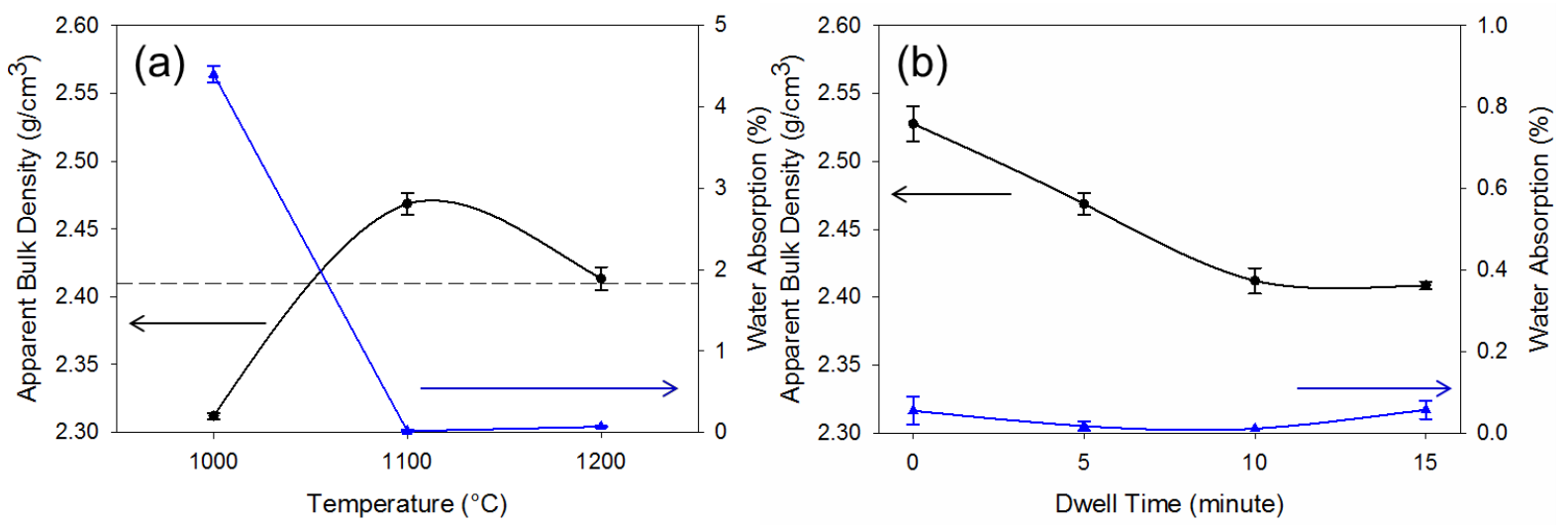

Figure 4. Physical properties (Apparent Bulk Density (ABD) and Water Absorption (WA)) of the samples sintered using the SPS as function of (a) temperatures and (b) dwell time at $1100^{\circ} \mathrm{C}$.

(a) $\mathrm{CS} 1175^{\circ} \mathrm{C}$

$5^{\circ} \mathrm{C} / \mathrm{min}, 15 \mathrm{~min}$ dwell

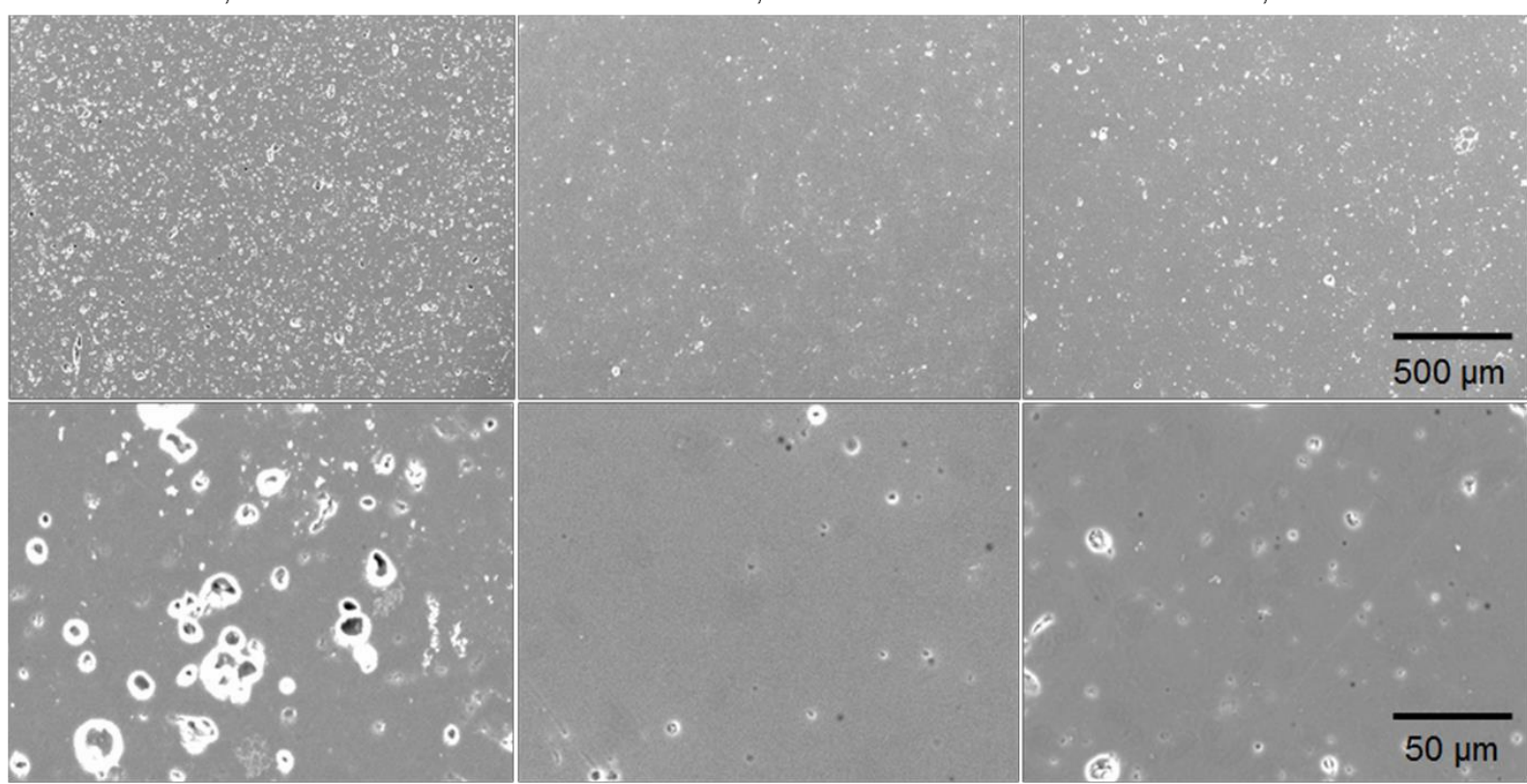

Figure 5 SEM images of porcelain samples sintered using (a) conventional sintering process (CS) with $5^{\circ} \mathrm{C} / \mathrm{min}, 15 \mathrm{~min}$ dwell and (b) SPS $1100^{\circ} \mathrm{C}$ sample with $100^{\circ} \mathrm{C} / \mathrm{min}$ and $5 \mathrm{~min}$ dwell and (c) SPS $1200^{\circ} \mathrm{C}$ sample with $100^{\circ} \mathrm{C} / \mathrm{min}$ and $5 \mathrm{~min}$ dwell. 
Comparing the microstructures of the SPSed samples (1100 and $1200^{\circ}$ C) with the CS

sample prepared at $1175^{\circ} \mathrm{C}$ (with $5^{\circ} \mathrm{C} / \mathrm{min}$ and $15 \mathrm{~min}$ of dwell time) shown in figure 5 , the difference in $A B D$ is clearly contributed from the dense microstructures. Low magnification images reveal numbers of pores trapped inside the CS sample even with $<0.05 \%$ of water absorption while the SPSed samples contain a reduced number and finer pores explaining its higher density. Few pores are observed in the SPSed samples while there many small pores are randomly distributed in the CS samples. The CS sample sintered at $1175^{\circ} \mathrm{C}$ contains a large number of pores $\left(23\right.$ pores $\left./ \mathrm{mm}^{2}\right)$ of size $>15 \mu \mathrm{m}$, while the SPSed sample at $1100^{\circ} \mathrm{C}$ contains 3 pores $/ \mathrm{mm}^{2}$ of size $>10$ $\mu \mathrm{m}$, and the SPSed sample at $1200^{\circ} \mathrm{C}$ shows 10 pores $/ \mathrm{mm}^{2}$ of size $>10 \mu \mathrm{m}$

from bloating).

\subsection{Mechanical properties}

Vickers hardness (HV) of the SPSed samples (Fig.6) is significantly improved compared with conventionally sintered $\left(\mathrm{CS}-1175^{\circ} \mathrm{C}\right)$ samples which is explained by their denser microstructures. For the samples sintered at $1100^{\circ} \mathrm{C}, \mathrm{HV}$ ranged between 6-7 GPa. Visual microstructural observations suggests that the SPSed samples prepared at $1100^{\circ} \mathrm{C}$ exhibited variation of densities from the outer layer and inner layer within their bulk at short dwell times ( $\leq 5$ minutes) and this is attributed to the rapid heating rate [20]. This effect was not observed in samples that had dwell times greater than10 min (Fig.6b).
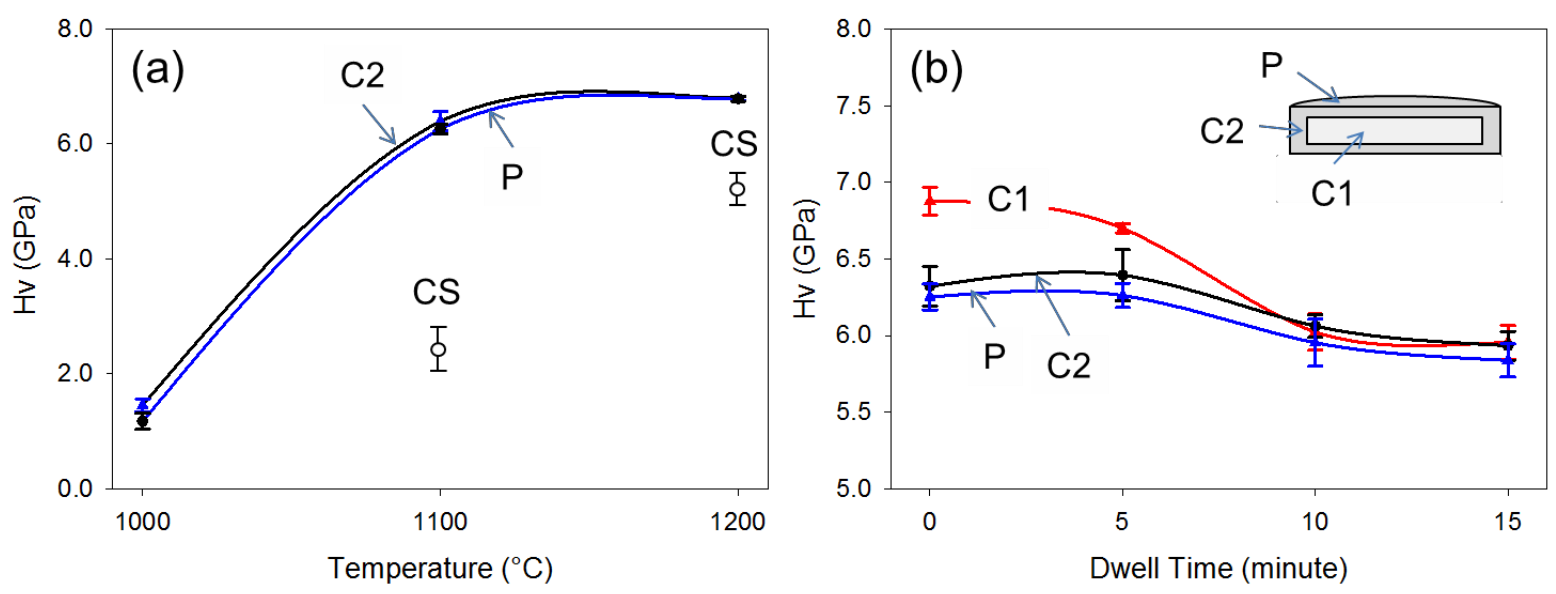

Figure 6 Vickers hardness (HV) of samples sintered using the SPS as a function of (a) sintering temperature and (b) dwell time at the sintering temperature $\left(1100^{\circ} \mathrm{C}\right)$ 
compared to conventionally sintered samples. 
The HV was carried out across the samples cross-section. As shown in the inset of Figure 6, the hardness was tested at $\mathrm{C} 1$ (sample centre mid-thickness), C2 (outer layer) and $\mathrm{P}$ (top surface in the centre). The results suggest slightly different hardness, with the outer layer having higher HV compared to centre. This could be attributed to different phase compositions suggested from XRD (Figure 7) which reveal that the outer layer of the samples contained more residual albite, indicated by the higher intensity of its peaks and the presence of only a small hump for the glass phase. According to SPS modeling work of the temperature distribution [20] during heating, the temperature at $\mathrm{C} 1$ is higher compared to $\mathrm{C} 2$ and $\mathrm{P}$, this results in preferential sintering near its location (with also increased pressure applied).

(a) 5 min dwell

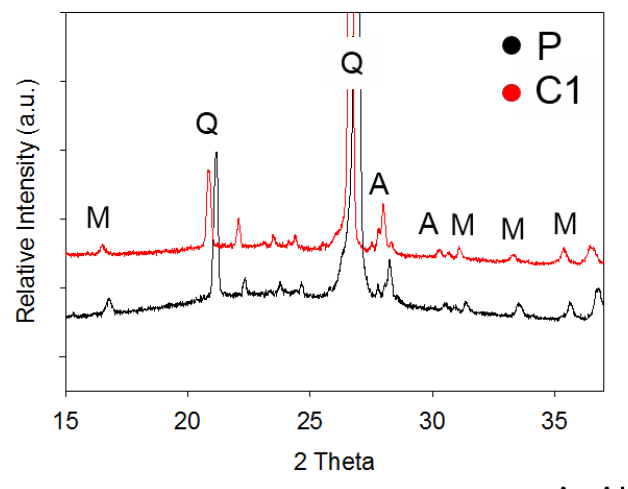

A=Albite, $M=$ Mullite, $Q=$ Quartz (b) 10 min dwell

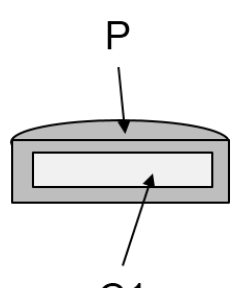

C1

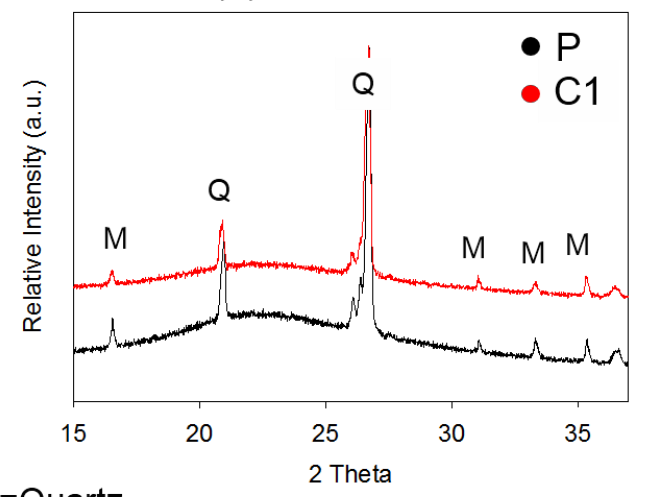

Figure 7 Vickers hardness (HV) of the SPSed samples sintered at $1100^{\circ} \mathrm{C}$ using different dwell times, the XRD patterns show mineralogical compositions of outer and inner layers.

HV shows a drop at all tested points for the samples dwelled 10 and 15 mins. HV is similar throughout the sample cross-section suggesting there is no uneven sintering at these dwell times. The glassy phase is completely formed (from melting of feldspars) under these sintering conditions as confirmed by XRD patterns (Figure 7b). Further formation of glassy phase (dwell time of 10-15 min) decreased HV because among the mineralogical phases in the porcelains (mullite, albite, quartz and glass), the glassy phase has the lowest HV [21-24].

Figure 8 shows images of indentations in the SPSed samples sintered at different temperatures. Cracks could not be observed in samples sintered at $1000^{\circ} \mathrm{C}$ due to their highly porous bodies so that it was not possible to determine Kıc. The radial 
cracks in the samples sintered at 1100 and $1200^{\circ} \mathrm{C}$ are clearly observed. Crack deflections are observed in the $1100^{\circ} \mathrm{C}$ samples, which produced higher fracture toughnesses compared to the $1200^{\circ} \mathrm{C}$ samples. This can be explained by the residual crystalline phases (albite, mullite and quartz) dispersed in the dense glassy matrix of the SPSed samples at $1100^{\circ} \mathrm{C}$. In the $1200^{\circ} \mathrm{C}$ sample straight cracks are observed, suggesting that the samples contain high level of glassy phase, which results in lower fracture toughness compared to the $1100^{\circ} \mathrm{C}$ samples. However, the fracture toughness of the SPSed samples is higher than the conventionally sintered samples because they exhibit higher density.

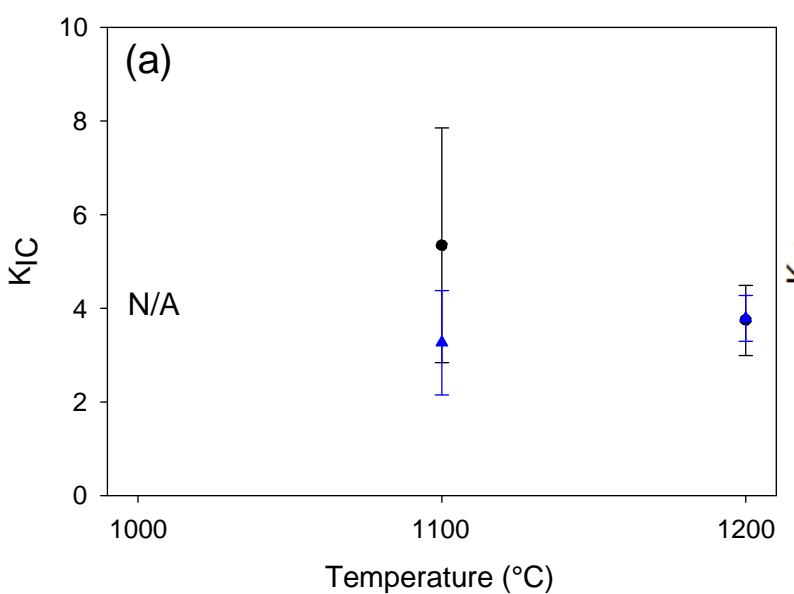

SPSed $1000^{\circ} \mathrm{C}$

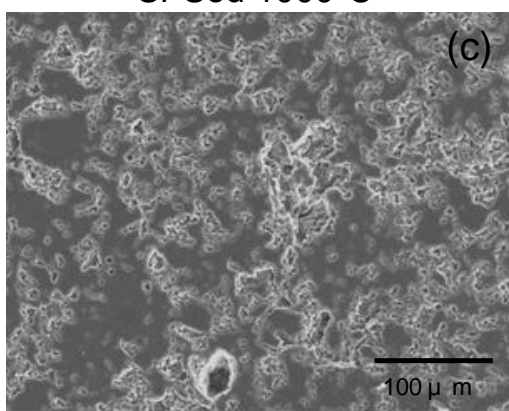

SPSed $1100^{\circ} \mathrm{C}$

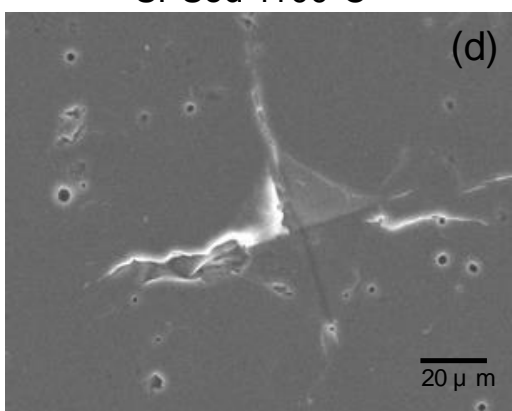

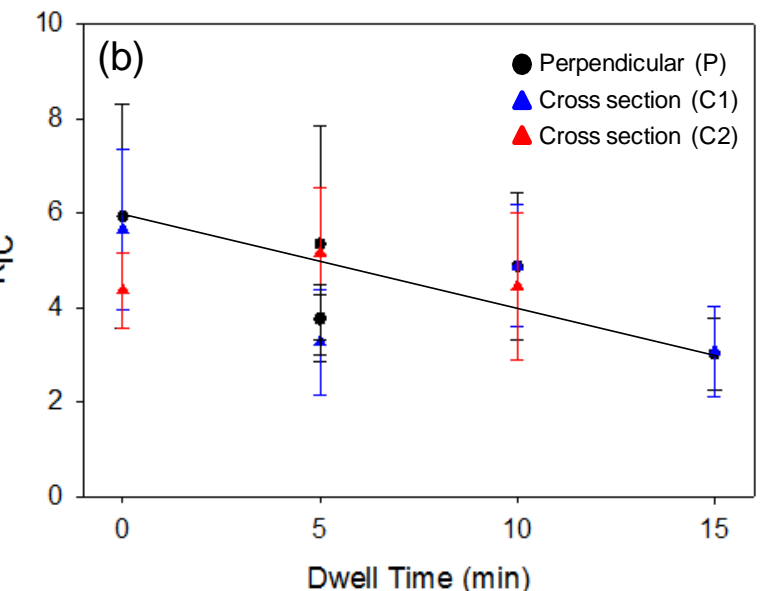

Dwell Time (min)

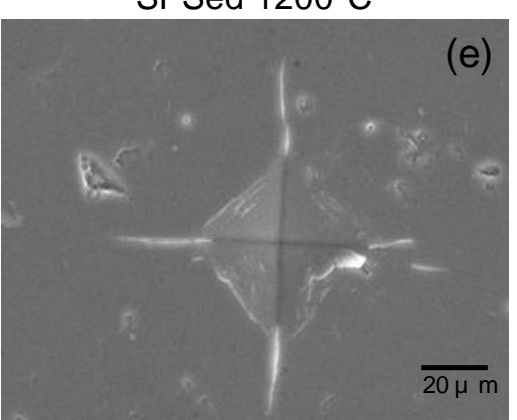

Figure 8 Fracture toughness $(\mathrm{KIC} \neg)$ of SPSed samples as a function of (a) temperature, and (b) dwell time. Images (c - e) show cracks generated labeled as SPSed 1000,1100 and $1200^{\circ} \mathrm{C}$. 
Table 1 Summary of material properties.

\begin{tabular}{lcccc}
\hline Minerals & $\begin{array}{c}\text { Density } \\
\left(\mathrm{g} / \mathrm{cm}^{3}\right)\end{array}$ & $\begin{array}{c}\mathrm{Hv} \\
(\mathrm{GPa})\end{array}$ & $\begin{array}{c}\mathrm{K} \mathrm{IC} \\
\left(\mathrm{MPa} \cdot \mathrm{m}^{1 / 2}\right)\end{array}$ & Ref. \\
\hline Albite & 2.62 & 6 & $0.75-1.3$ & 25 \\
Mullite & 3.14 & 10 & $2-2.8$ & 22,26 \\
Quartz & 2.65 & 12 & $1.6-2.4$ & 25 \\
Glass & 2.39 & $3-6$ & 0.7 & 24 \\
\hline
\end{tabular}

In samples sintered at $1100^{\circ} \mathrm{C}, \mathrm{K} \mathrm{c}$ decreases slightly as a function of dwell time (Fig $8 b)$. The presence of residual feldspar, quartz and mullite in the glassy matrix tends to increase the fracture toughness of the samples by crack deflection while as more glass forms the fracture toughness decreases because glass has the lowest toughness among the phases present in the porcelains.

As previously mentioned, the densification of porcelains depends on the formation of glass phase. When the liquid glass phase is formed the surface tension brings the solid particles (mullite, residual feldspar and quartz) together creating volume shrinkage and close pores so that a large fraction of the pores is filled with glass.

The pressure, furthermore, forces liquid glass phase to fill the pores increasing the densification rate. The molten glass flows into capillaries in proportion to the applied pressure and densifies the porcelain. Densification from viscous flow under applied pressure can be expressed by the following equation [27];

$$
\frac{d \rho}{d t}=\frac{3 P}{4 \eta}(1-\rho)
$$

where $\rho$ is density, $\mathrm{P}$ is the applied pressure, $\eta$ is viscosity of the molten glass and

$\rho$ ) is volume fraction of porosity. Note that increasing pressure can result in increased viscosity but to increase viscosity of molten glass significantly, pressure has to be high (GPa) [28] thus in our study, the glass viscosity is considered to be constant with increasing pressure. Thus the increased densification is solely governed by applied pressure. Although, there is always some remnant porosity as trapped gas cannot 
escape through the vitreous phase. 


\section{Conclusion}

SPS is an effective process to produce highly-dense porcelain requiring shorter sintering times compared to conventional sintering processes. The applied pressure has a huge influence on the densification. SPSed samples exhibit improved physicomechanical properties resulting from a combination of the highly-dense microstructure and mineralogical composition.

\section{Acknowledgements}

WL was supported by Imperial College London funding no. MMRE_PG54200. S.G. was supported by EPSRC (EP/K008749/1, XMat). MJR would like to acknowledge the support of Sunchon National University, South Korea, through the BK21+ programme. 


\section{References}

1. W.M. Carty, and U. Senapati, Porcelain-raw materials, processing, phase evolution, and mechanical behaviour, J. Am. Ceram. Soc. 81 (1) (1998) 3- 20.

2. Y. Iqbal, and W.E. Lee, Microstructural evolution in triaxial porcelain, J. Am. Ceram. Soc. 83 (12) (2000) 3121-3127.

3. W.D. Kingery, H.K. Bowen, and D.R. Uhlmann, Introduction to Ceramics, Wiley, NY, 1976.

4. F.H. Norton, Fine Ceramics: Technology and Applications, 2nd ed., Robert E.Krieger Publishing Company, Inc., FL, 1978.

5. M.N. Rahaman, Sintering of ceramics, CRC Press, FL, 2008.

6. W. Lerdprom, Firing of Porcelain: M.S Thesis, New York State College of Ceramics at Alfred University, Alfred, NY, 2014.

7. K. Srikrishna, G. Thomas, R. Martinez, M. P. Corral, S. De Aza, and J. S. Moya, Kaolinite-mullite reaction series: a TEM study, J. Mat Sci. 25 (1) (1990) 607-612.

8. K. Okada, N. Otsuka, and J. Ossaka, Characterization of spinel phase formed in the kaolin-mullite thermal sequence, J. Am. Ceram. Soc. 69 (10) (1986) C-251C-253.

9. A.K. Chakravorty, and D.K. Ghosh, Kaolinite- mullite reaction series: the development and significance of a binary aluminosilicate phase, J. Am. Ceram. Soc. 74 (6) (1991) 1401-1406.

10. Y. Iqbal, and W.E. Lee, Fired porcelain microstructure revisited, J. Am. Ceram. Soc. 82 (12) (1999) 3584-3590.

11. S. Grasso, Y. Sakka, and G. Maizza, Electric current activated/assisted sintering (ECAS): A review of patents 1906-2008, Sci. Tech. Adv. Mat. 2009. 10 (5).

12. G. Tsukada, H. Sueyoshi, H. Kamibayashi, M. Tokuda, and M. Torii, Bending strength of zirconia/porcelain functionally graded materials prepared using spark plasma sintering. J. Dent. 42 (12) (2014) 1569-1576.

13. A.G. Evans, and E.A. Charles, Fracture toughness determinations by indentation. J. Am. Ceram. Soc. 59 (7-8) (1976) 371-372.

14. C. Chen, G. Lan, and W. Tuan, Microstructural evolution of mullite during the sintering of kaolin powder compacts. Ceram. Int. 26 (7) (2000) 715-720.

15. C.M. Stevenson, and M. Gurnick, Structural collapse in kaolinite, montmorillonite and illite clay and its role in the ceramic rehydroxylation dating of low-fired earthenware. J. Arch. Sci. 69 (2016) 54-63.

16. S. Sperinck, P. Raiteri, N. Marks, and K. Wright, Dehydroxylation of kaolinite to metakaolin-a molecular dynamics study. J. Mat. Chem. 21 (7) (2011) 21182125. 
17. H. Lee, W.M. Carty, Glass phase composition in porcelains and correlation with firing temperature, in: Proceedings of the 106th Annual Meeting and Exposition of the American Ceramic Society, April 18- 21 2004, Indianapolis, Indiana, USA, 2004.

18. W.M. Carty, Observations on the glass phase composition in porcelains, Mater. Equip. Whitewares: Ceram. Eng. Sci. Proc. 23 (2) (2009) 74- 79.

19. V. Colorado, Fast firing of porcelain: M.S Thesis, New York State College of Ceramics at Alfred University, Alfred, NY, 2014.

20. S. Grasso, C.Hu, G. Maizza, B. Kim, and Y. Sakka, Effects of pressure application method on transparency of spark plasma sintered alumina. J. Am. Ceram. Soc. 94 (5) (2011) 1405-1409.

21. F.J. Sousa, M. Dal Bó, P. O. Guglielmi, R.Janssen, and D.Hotza, Characterization of Young's modulus and fracture toughness of albite glass by different techniques. Ceram. Int. 40 (7) (2014) 10893-10899.

22. S. Kanzaki, H. Tabata, T. Kumazawa, and S. Ohta, Sintering and mechanical properties of stoichiometric mullite. J. Am. Ceram. Soc. 68(1) (2006) C6- C7.

23. R.C. Bradt, D.P.H. Hasselman, D.Munz, M.Sakai, and V.Y. Shevchenko, (Eds.), Fracture Mechanics of Ceramics: Fracture fundamentals, high-temperature deformation, damage, and design. Springer Science \& Business Media 2013.

24. A.T. Akono, N.X. Randall, and F.J. Ulm, Experimental determination of the fracture toughness via microscratch tests: Application to polymers, ceramics, and metals. J. Mat. Res. 27(02) (2012) 485-493.

25. J.G. Spray, Frictional melting processes in planetary materials: From hypervelocity impact to earthquakes. Annu. Rev. Earth Planet. Sci. 38 (2010) 22154.

26. R. Ruh, K.S. Mazdiyasni, and M.G. Mendiratta, "Mechanical and Microstructural Characterization of Mullite and Mullite-SiC-Whisker and ZrO2Toughened-Mullite-SiC-Whisker Composites." J. Amer. Ceram. Soc. 71(6)

503-512.

27. W. Kingery, J. Woulbroun, and F. Charvat, Effects of applied pressure on densification during sintering in the presence of a liquid phase. J. Am. Ceram. Soc. 46(8) (1963) 391-395.

28. G. Wolf, and P. McMillan, Pressure effects on silicate melt structure and properties. Rev. Mineral. Geochem. 32(1) (1995) 505-561. 

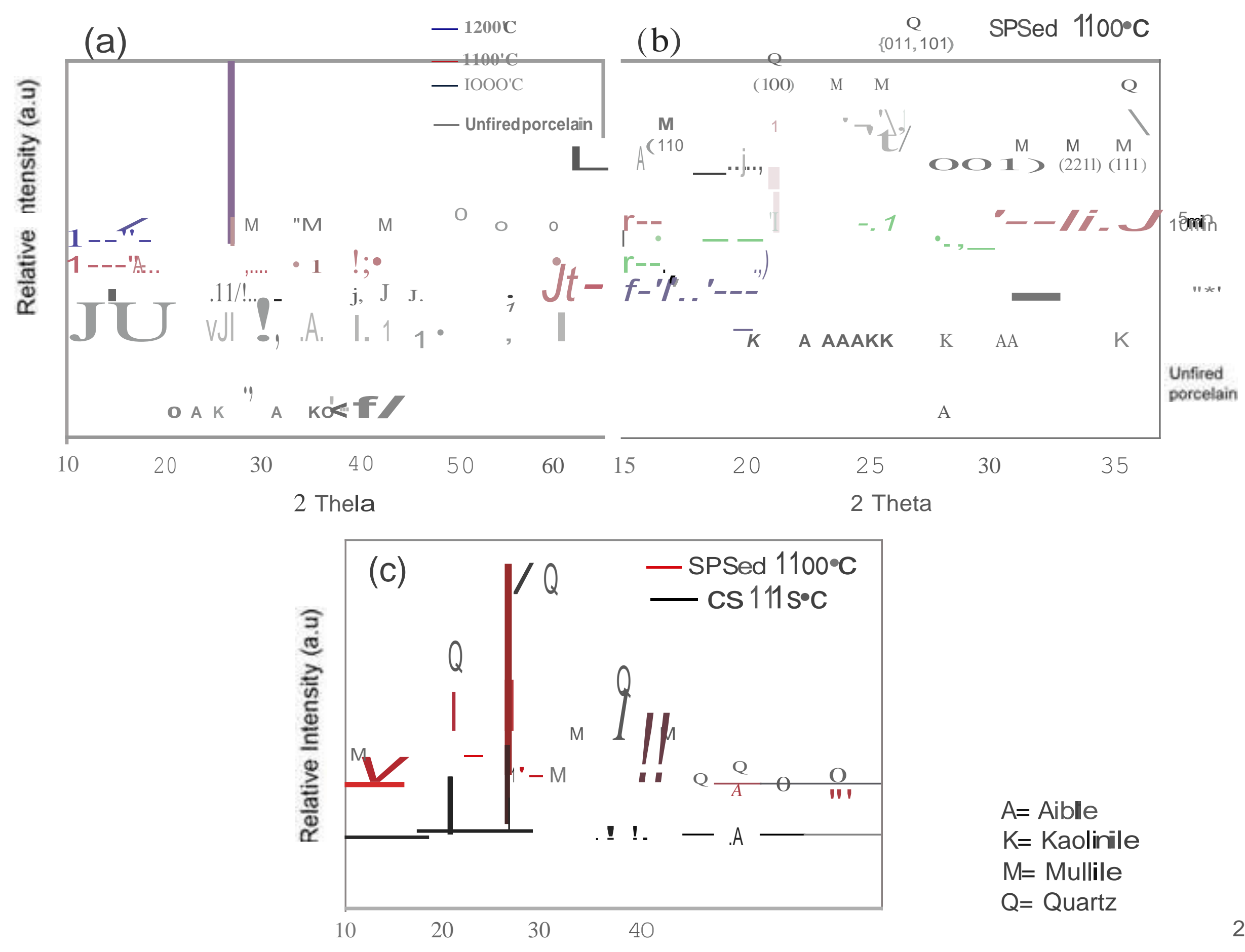

$A=$ Aible

$\mathrm{K}=$ Kaolinile

$\mathrm{M}=$ Mullile

$Q=$ Quartz 


.

. . . .

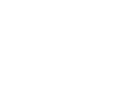

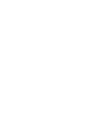
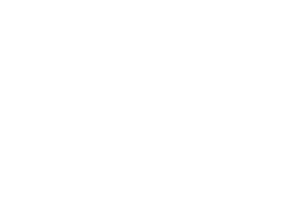

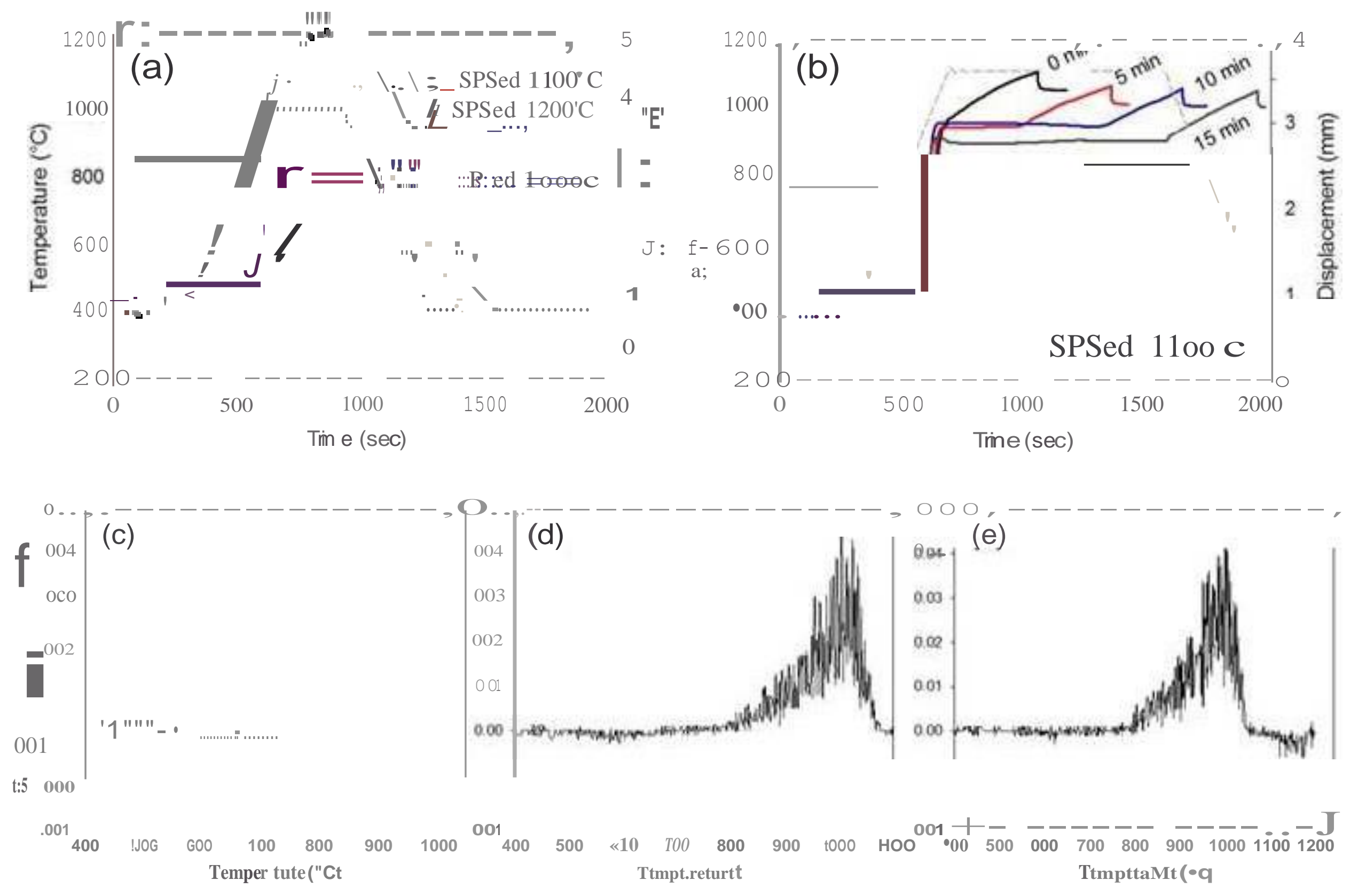

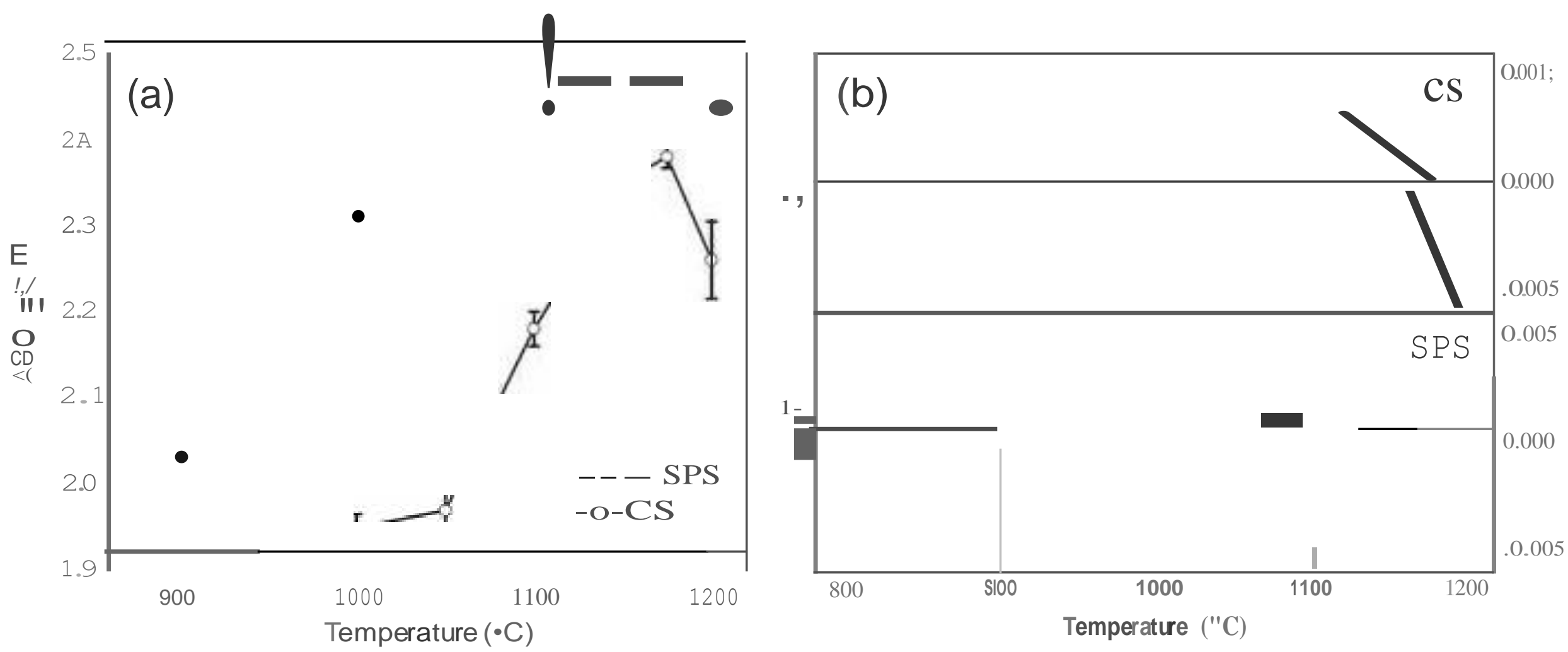

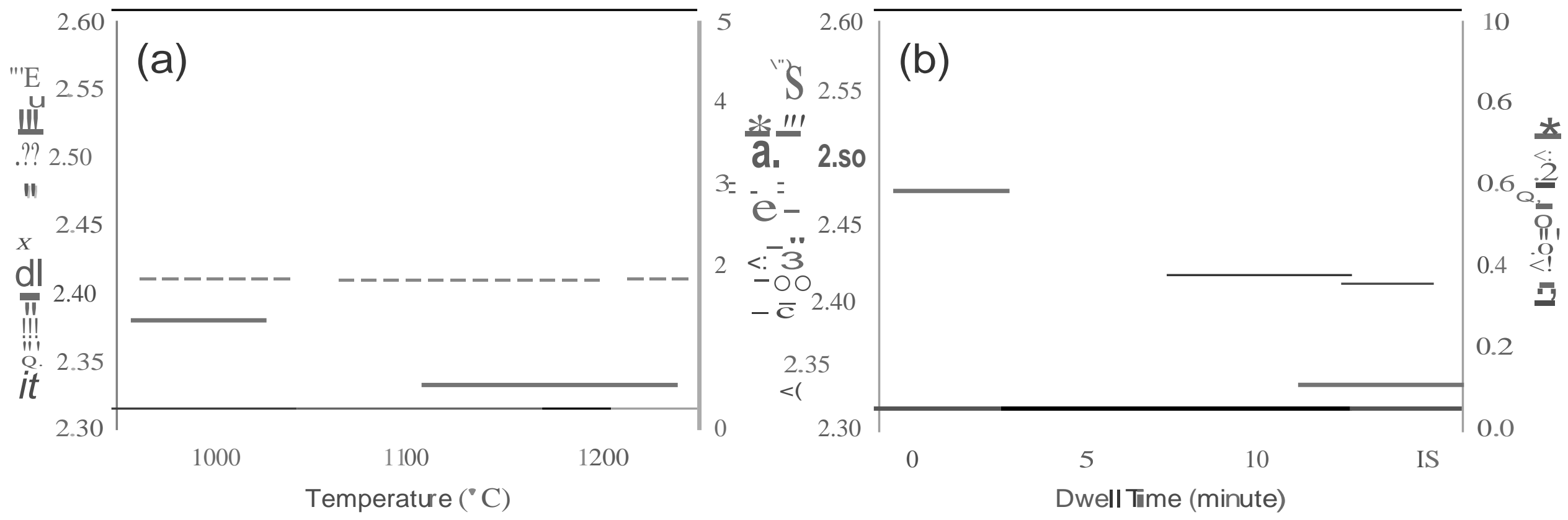


\section{(a) $\operatorname{CS} 1175^{\circ} \mathrm{C}$}

$5^{\circ} \mathrm{C} / \mathrm{min}, 15 \mathrm{~min}$ dwell
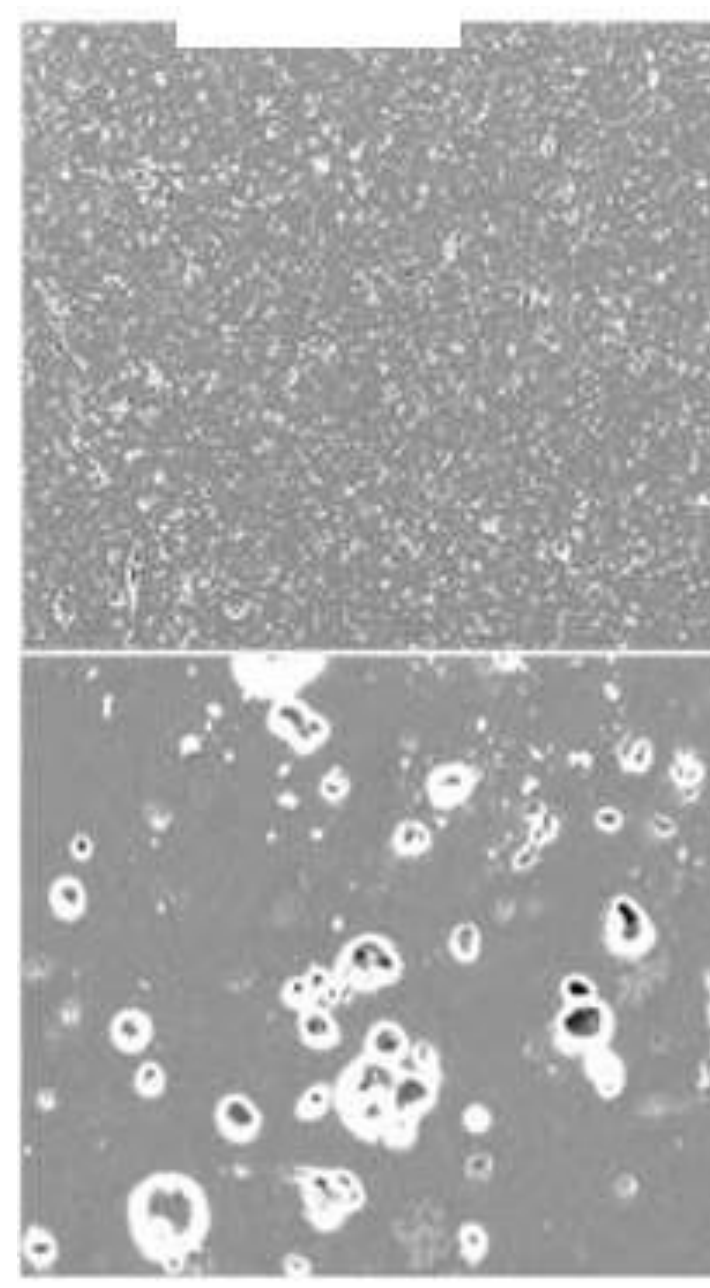

(b) $\mathrm{SPS} 1100^{\circ} \mathrm{C}$

$100^{\circ} \mathrm{C} / \mathrm{min}, 5 \mathrm{~min}$ dwell (c) SPS $1200^{\circ} \mathrm{C}$

$100^{\circ} \mathrm{C} / \mathrm{min}, 5 \mathrm{~min}$ dwell

\section{.}

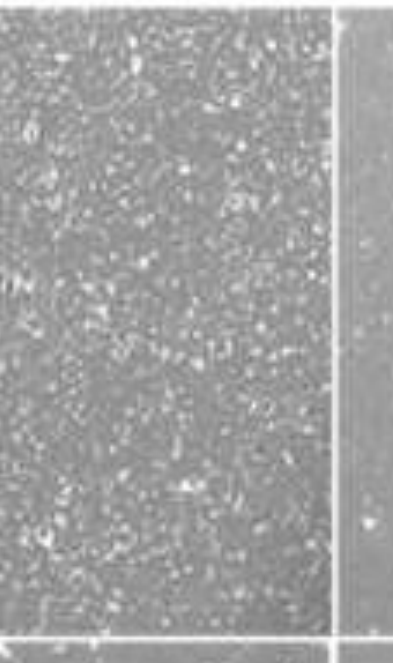

?

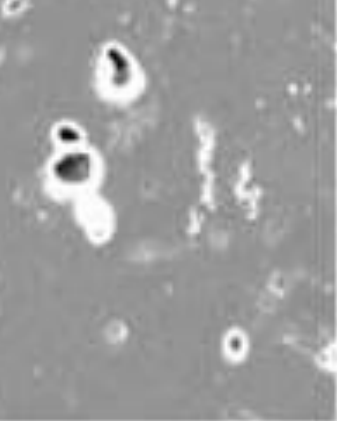

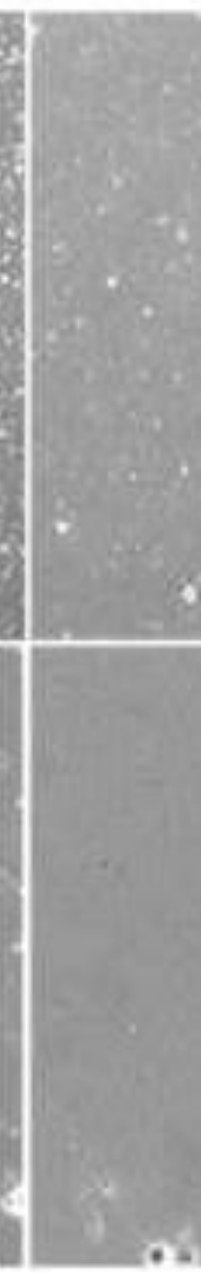
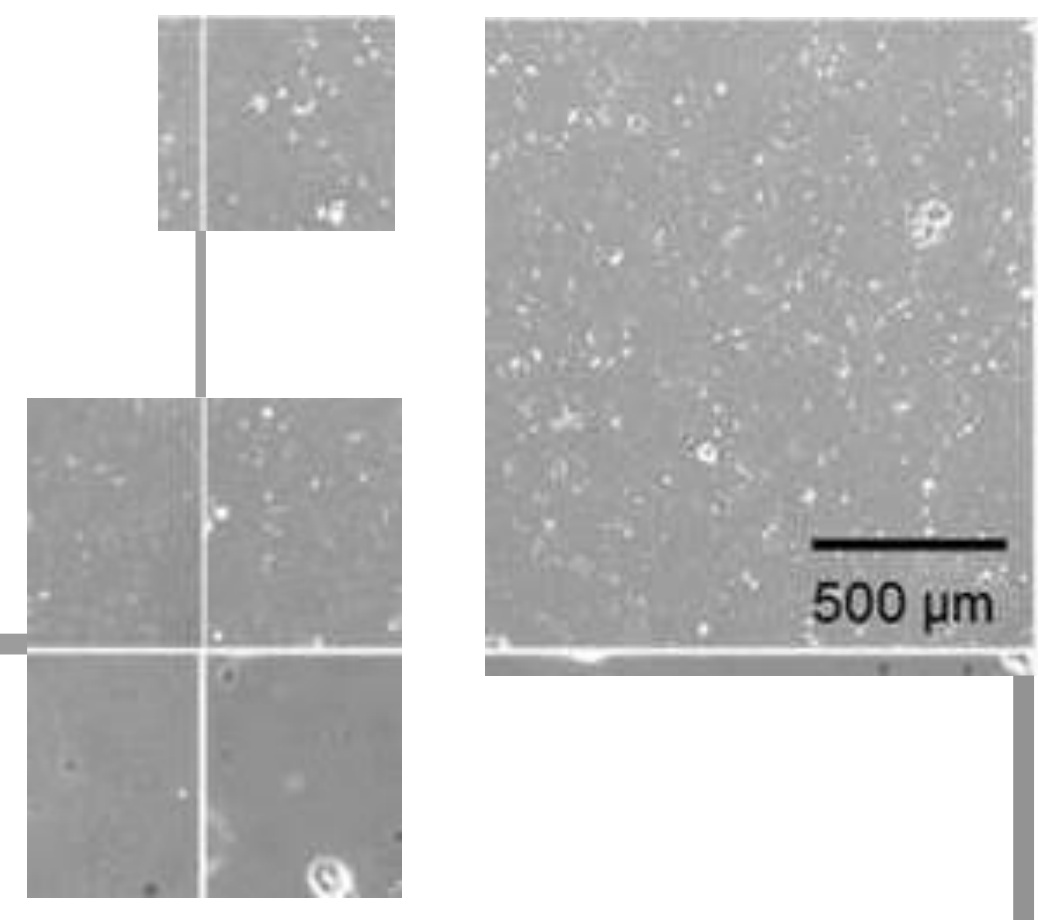

C.

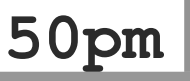



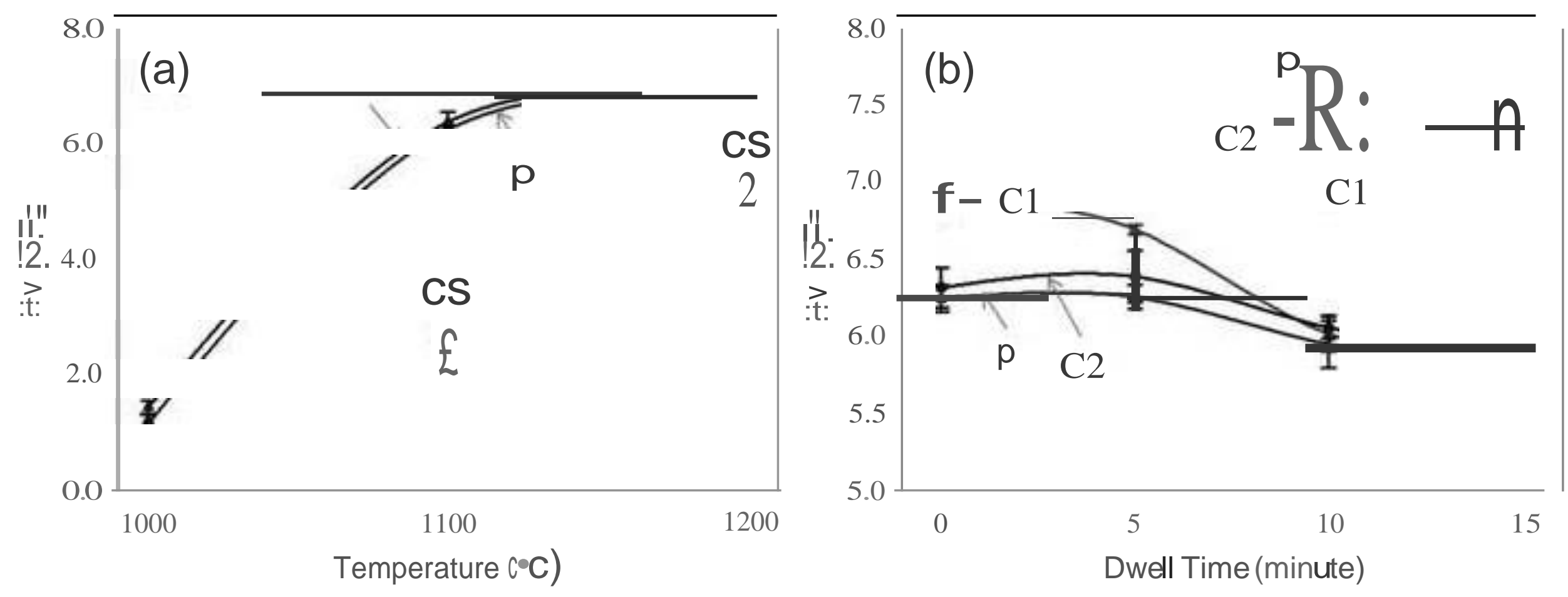
(a) 5 min dwel

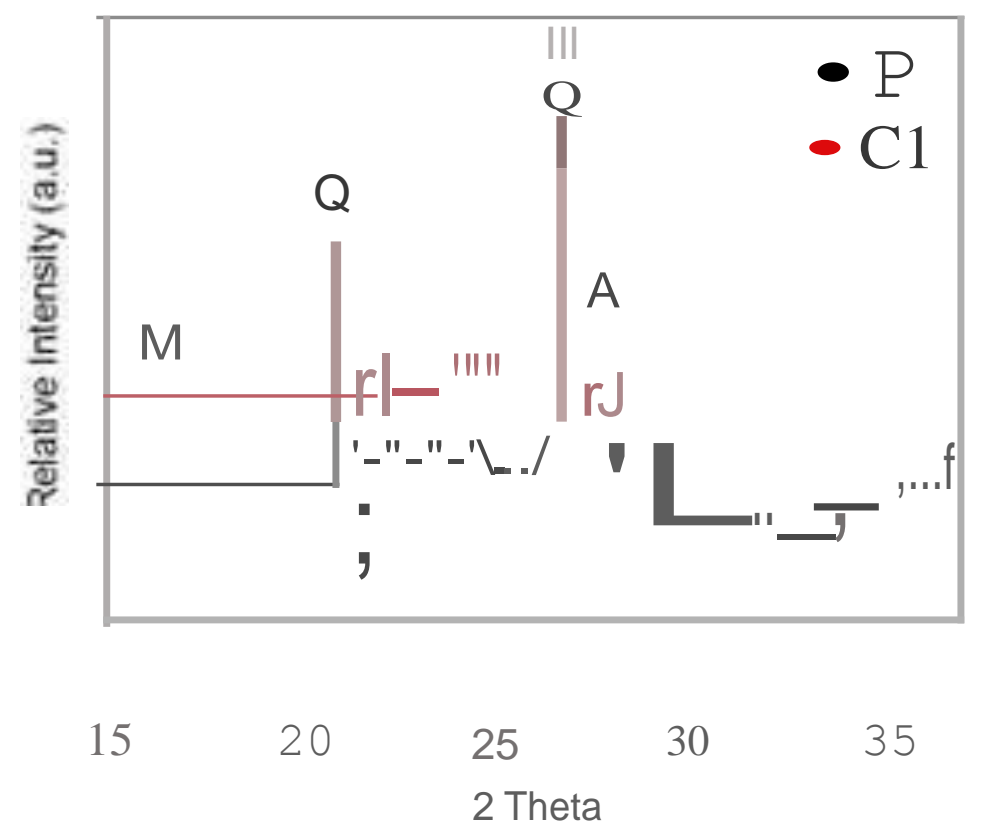

(b) 10 min dwell

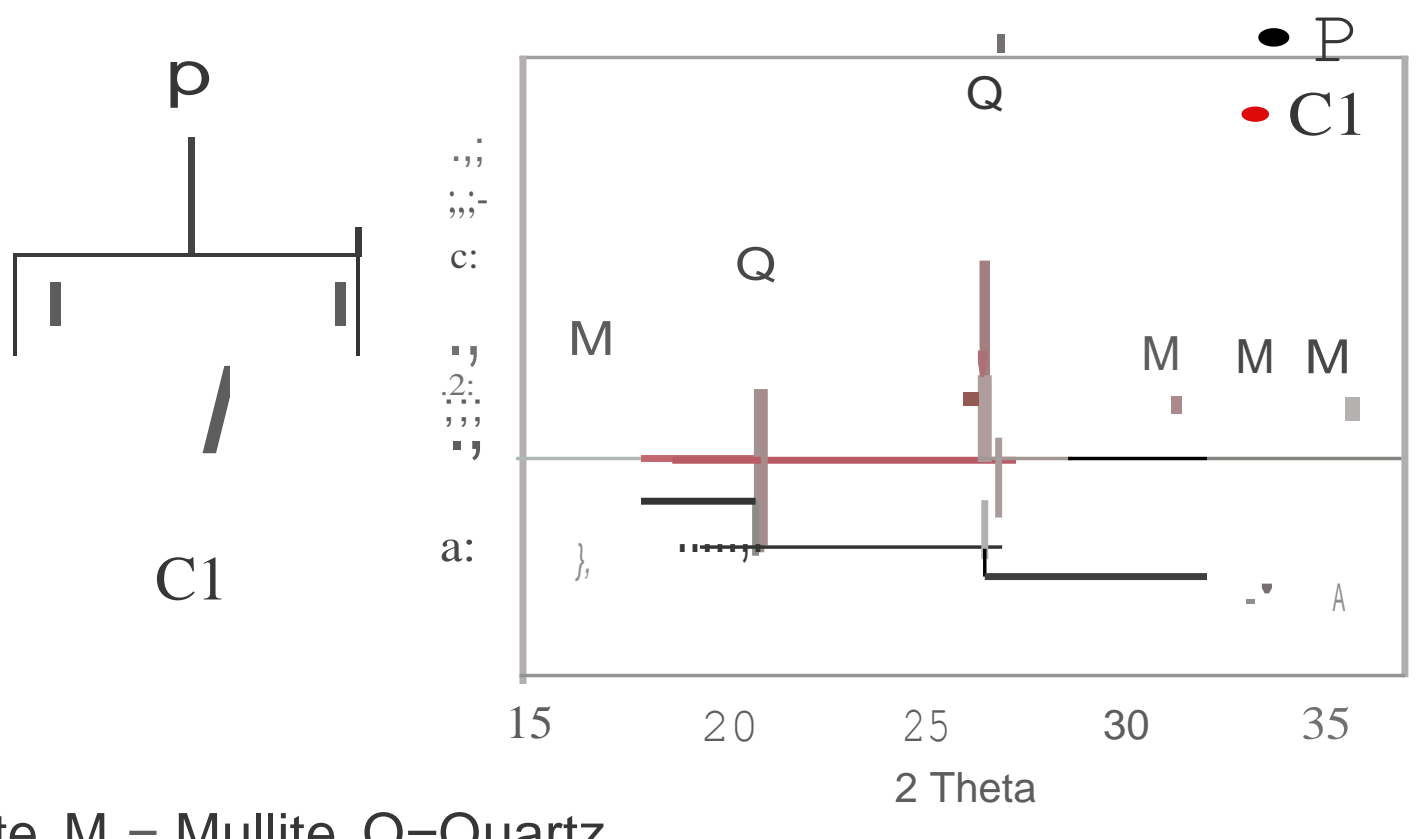

$A=$ Aibi te, $M=$ Mullite, $Q=$ Quartz 

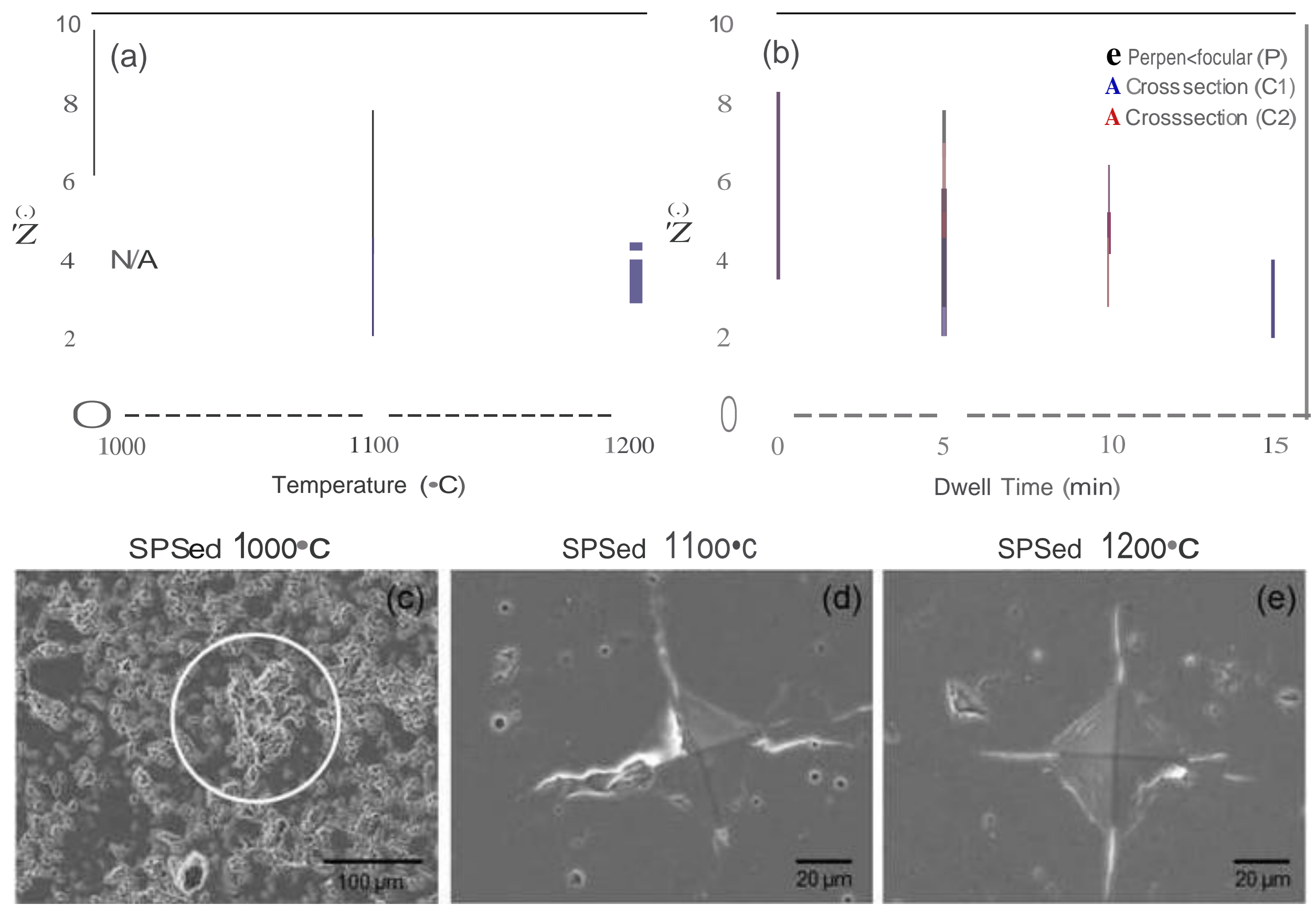